\title{
HfIB Gene-Based Phytopathogenic Classification of 'Candidatus Phytoplasma mali' Strains and Evidence that Strain Composition Determines Virulence in Multiply Infected Apple Trees
}

\author{
Erich Seemüller ${ }^{1}$, Maren Kampmann', Emese Kiss ${ }^{2}$, and Bernd Schneider ${ }^{1}$ \\ 'Julius Kuehn Institute, Federal Research Centre for Cultivated Plants, Institute for Plant Protection in Fruit Crops and \\ Viticulture, D-69221 Dossenheim, Germany, ${ }^{2}$ Plant Protection Institute of the Hungarian Academy of Science, H-1525 \\ Budapest, Hungary
}

Submitted 18 May 2011. Accepted 28 June 2011.

\begin{abstract}
Analysis of pathological and molecular data of 'Candidatus Phytoplasma mali' accessions from 27 apple trees differing considerably in symptomatology was used to molecularly characterize and classify strains of the infecting apple proliferation phytoplasma. Single-strand conformation polymorphism and sequence analysis of a variable fragment of ATP00464-type $h f l B$ gene revealed that these sources consisted of single-strain and multiple-strain accessions that occurred in similar numbers. The latter group was composed of two to five distinct strains. Analysis of cloned sequences of mild and severe single-strain accessions resulted in two groups of reads that clustered, according to their virulence, distantly in the phylogram. Based on this data, the clustering patterns of multiple-strain accession sequences indicated that nearly all of them were composed of mild and severe strains. The distinct clustering of sequences representing mild and severe strains was associated with a range of molecular markers at the nucleotide and amino acid level. Data indicate that the virulence of multiple-strain accessions is determined by the ratio of the occurring mild and severe strains in that mild accessions were characterized by the predominance of sequences representing mild strains and vice versa. There is evidence that shifts in the population and other events may occur that drastically alter virulence of multiple-strain accessions.
\end{abstract}

Phytoplasmas are phloem-residing and uncultivated bacteria of the class Mollicutes that are transmitted by phloem-feeding insects and are associated with diseases of hundreds of plant species. Apple proliferation (AP), caused by 'Candidatus Phytoplasma mali', is one of the most important phytoplasmal diseases in Europe. AP induces a range of symptoms that are either specific, such as witches' brooms, rosettes, and enlarged stipules, or largely nonspecific, such as foliar reddening, yellowing, growth suppression, and undersized fruits. However, symptom expression is often subject to fluctuation. Witches'

Nucleotide sequence data for 454-bp fragments of $h f l B$ gene ATP00464 is available in the GenBank, EMBL, and DDBJ databases under accession numbers FR828576 to FR828675. Full-length sequences of ATP00464type genes and its paralogs ATP00034 and ATP00457 are available under accession numbers FR863636 to FR863645.

Corresponding author: E. Seemüller; Telephone: +49 6221 8680550; Fax: +49 6221 8680515; E-mail: erich.seemueller@jki.bund.de brooms and undersized fruits are typical for newly diseased trees and can often be observed in the first few years of disease. Then, trees may recover and may show no or only mild symptoms for shorter or longer periods, after which severe symptoms may reappear (Carraro et al. 2004; Seemüller et al. 1984a). Symptom development also depends on the virulence of the infecting AP phytoplasma strains. As recently reported, randomly collected ' $\mathrm{Ca}$. P. mali' accessions differed greatly in aggressiveness when graft-inoculated onto healthy clonal apple rootstocks. After 12 years of observation, the accessions were classified into three groups: i) avirulent or mildly virulent, ii) moderately virulent, and iii) strongly virulent. Vigor and performance of trees infected by the first group were virtually indistinguishable from healthy controls and showed only occasionally mild symptoms (Seemüller and Schneider 2007).

' $C a$. P. mali' is, at the level of ribosomal DNA sequences, a homogenous species throughout Europe (Seemüller and Schneider 2004). To elucidate the molecular diversity within this taxon, several other approaches have been employed. Typing based on restriction fragment length polymorphism analysis of ribosomal protein genes (Martini et al. 2008), on sequences of nonribosomal loci including the imp, aceF, pnp, and secY genes (Danet et al. 2007), and a putative nitroreductase gene (Jarausch et al. 1994, 2000) revealed genetic differences in ' $C a$. P. mali'. Two major subgroups of ' $C a$. P. mali', designated AT (or AT-1) and AP, and additional subtypes have been delineated (Jarausch et al. 1994, 2000; Kison et al. 1994; Martini et al. 2008). However, the genotypes defined in these efforts were unrelated to phenotypical traits such as virulence and other pathological characteristics including symptomatology and host specificity.

High resolution of ' $\mathrm{Ca}$. P. mali' genotypes was achieved by single-strand conformation polymorphism (SSCP) analysis of an $h f l B$ (synonym $f t s H$ ) gene fragment (Schneider and Seemüller 2009; Seemüller et al. 2010). hflB genes encode membrane-associated ATP- and $\mathrm{Zn}^{2+}$-dependent proteases that are conserved among bacteria and are involved in membraneassociated processes such as protein secretion and membrane protein assembly as well as adaptations to nutritional conditions and osmotic stress (Bai et al. 2006). In most bacteria, $h f l B$ is a single-copy gene, whereas in phytoplasma genomes, between six and 24 copies have been identified (Arashida et al. 2008; Bai et al. 2006; Oshima et al. 2004; Tran-Nguyen et al. 2008). On the ' $C a$. P. mali' AT chromosome (GenBank accession number CU469464.1), 12 full-length or truncated $h f l B$ 
genes were annotated and were assigned to five groups of paralogs (Kube et al. 2008). A variable fragment of gene ATP00464 (paralogs are ATP00034, ATP00454, and ATP00457) was selected for analyzing strain variability in ' $\mathrm{Ca}$. P. mali' by SSCP and sequence analysis. A total of 20 different SSCP patterns were obtained using this sequence (Schneider and Seemüller 2009). In continuing this work, we identified DNA samples yielding more complex SSCP profiles that suggested the presence of multiple infections in a single tree. Cloning of polymerase chain reaction (PCR) products of such samples resulted in clone populations showing distinct profile polymorphisms. Sequences of cloned $h f l B$ gene fragments of such accessions were diverse and clustered distantly when subjected to phylogenetic analysis. The collective data indicate that they were composed of two or three distinct ' $\mathrm{Ca}$. P. mali' strains. The occurrence of multiple infections and their diversity was confirmed by analyzing the single-copy imp gene (ATP00050) that encodes the immunodominant membrane protein Imp of the AP agent (Seemüller et al. 2010).

Recent work also suggested that multiple infections are of pathological relevance, probably due to antagonistic strain interactions leading to shifts in the populations. Trees infected by one of the accessions examined were largely nonsymptomatic for many years. During this time, two distinct strains were identified, separately or jointly. Following transmission of this accession to periwinkle (Catharanthus roseus) and tobacco (Nicotiana tabacum and N. occidentalis), these strains grew specifically in periwinkle or tobacco. In apple, mainly as a consequence of altered growing conditions, a third strain characterized by a unique SSCP profile, a unique $h f l B$ gene sequence, and high virulence was identified (Seemüller et al. 2010). These observations are likely to contribute to a better understanding of the phenomenon of inconsistent symptomatology and recovery. The presumable interferences between phytoplasma strains observed are in agreement with the results of early work with aster yellows agents, in which suppression of other strains, mutual suppression, and cross protection activity is reported (Freitag 1964; Kunkel 1955; Valenta 1959).

In the research presented here, we employed, as in previous work (Schneider and Seemüller 2009; Seemüller et al. 2010), SSCP and sequence analysis of a variable region of the ATP00464-type $h f l B$ gene to characterize the AP phytoplasmas present in singly and multiply infected trees. Symptomatology and the course of disease of the trees examined differed greatly, ranging from being nonsymptomatic to showing severe symptoms. By linking virulence of the infecting phytoplasmas with their SSCP and sequence data, it was possible to distinguish and classify mild and severe strains at the molecular level. In addition, evidence was obtained that interaction of mild and severe strains in multiply infected trees that results in shifts in the populations are determining ' $C a$. P. mali' virulence.

\section{RESULTS}

\section{Specificity of PCR amplification.}

Amplification of full-length ATP00464-type genes and its paralogs ATP00034, ATP00454, and ATP00457 with the primers designed succeeded for ATP00464 and ATP00457 from all strains and for ATP00034 and ATP00454 from some of the strains. Amplification was always specific for the respective gene. Phylogenetic comparison revealed that strain sequences from each ATP00034, ATP00457, and ATP00464 form a coherent group that clusters in a distinct subclade. DNA sequence identity within these groups ranged from 94.4 to $99.8 \%$ whereas the identity between the genes ranged from 48.7 to $85.7 \%$. In contrast to these full-length genes with sizes of approximately 1,800 bp, the ATP00454-type genes were truncated and consisted of 330- to 550-bp fragments. Alignment of ATP00464type genes and its paralogs also showed that primers fHflB_3 and rHflB3, which were used to amplify the 528-bp fragment employed in the phytopathogenic classification, are specific for the ATP00464-type.

\section{Nature of accessions and phylogenetic clustering of the components.}

As expressed by number and mobility of the bands, SSCP analysis of the PCR-amplified 528-bp $h f l B$-gene fragments revealed considerable diversity of DNA profiles in the accessions examined, similar to that reported previously (Seemüller et al. 2010). Following cloning and SSCP analysis of the cloned fragments, homogenous and heterogeneous clone populations were obtained (Fig. 1A). Sequence analysis showed that cloned fragments of accessions characterized by similar profiles (e.g. 2/4, 3/2, 3/3) have identical or nearly identical DNA sequences that cluster closely together in the phylogram. In confirming previous findings (Seemüller et al. 2010), some accessions exhibiting polymorphic SSCP profiles (e.g., Rol and 3/8 [Fig. 1A]) showed nearly identical sequences as well (Fig. 2). Both categories are in the following referred to as single-strain accessions or strains. They are listed in Table 1, together with the periwinkle-maintained reference strains AP15 and AT, which showed homogenous SSCP profiles and identi-

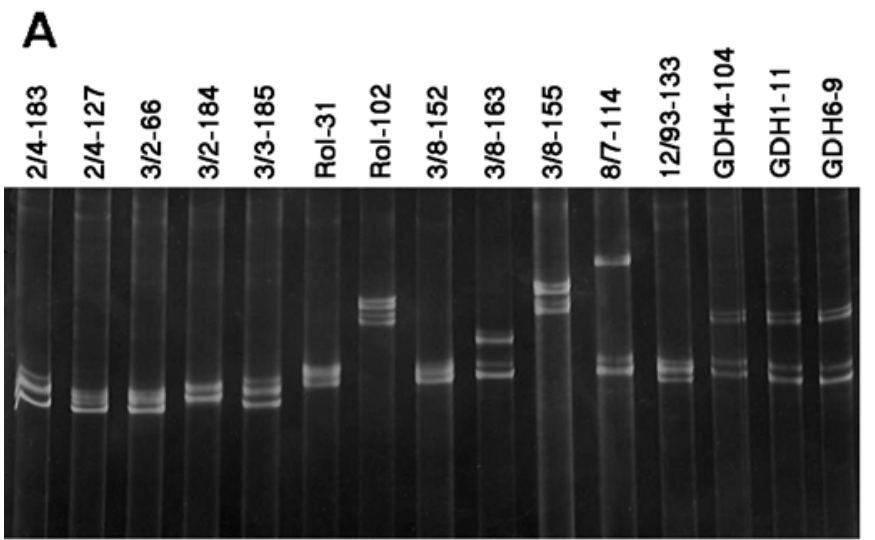

B
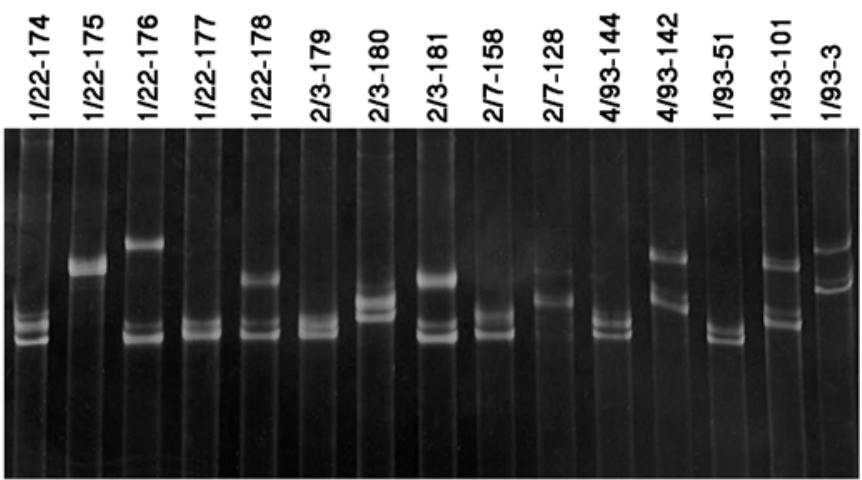

Fig. 1. Single-strand conformation polymorphism profiles of cloned 528-bp $h f l B$ gene fragments of 'Candidatus Phytoplasma mali' accessions. A, Examples of profiles of homogenous (accessions 2/4, 3/2, 3/3, 8/7, 12/93, 3/1, GDH1, and GDH6) and polymorphic (accessions Rol and 3/8) single-strain accessions from infected apple trees. B, Examples of polymorphic profiles of multiple-strain accessions from infected apple trees. Extension of the accession designation shows clone number. 
cal or nearly identical sequences (Fig. 2). The nucleotide sequence similarity of strains assigned to this accession group ranged from 99.2 to $100 \%$.

SSCP analysis of PCR products of the remaining accessions yielded profiles that were often more complex than those described above. Following cloning, heterogeneous clone popu-



lations were obtained (Fig. 1B). DNA sequences of such diverse clones showed a considerably higher variability than clones of the above group. They cluster in the phylogram at two (accessions 3/93, 8/93, 14/93, GDH1-CP), three (accessions 2/3, 2/7, $4 / 93,10 / 93,13 / 93,17 / 93$ ), four (accession 1/22), or five (accession 1/93) distant positions (Fig. 2). The diverse groups within accessions differ in 1.4 to $6.6 \%$ of the nucleotide positions and are in their majority in the range of ' $\mathrm{Ca}$. P. mali' reference strains AP15 and AT that share 96.6\% sequence similarity. For this reason, the distantly clustering genotypes of multiple-strain accessions are in the following referred to as strains. Additional information on the relationship of SSCP and sequence data and on the $h f l B$ gene-related variability of ' $C a$. P. mali' strains is provided elsewhere (Seemüller et al. 2010).

\section{Variability of virulence and course of disease.}

Symptomatology of the trees infected by the three groups of accessions differed considerably during the observation period. The pathological data of these groups are separately summarized for single-strain accessions (Table 1) and multiple-strain accessions (Table 2). The trees inoculated in 1993 with the first group of accessions responded very differently to infection in the field-growing period by showing average disease indices (DI) between 0.1 and 2.8. There was little variation within the trees at this time, indicating stable conditions of the infecting phytoplasma populations. However, when mild accession 4/93 (DI 0.3) was transmitted to trees subsequently grown in the greenhouse, all of them developed permanently severe symptoms (DI 2.2). In addition, following graft-transmission of mild accession 1/93 (DI 0.2) and greenhouse-growing, one of five inoculated trees developed witches' broom symptoms (DI 2.2), whereas the others remained largely nonsymptomatic. In contrast, highly virulent accessions 12/93 and 14/93 developed severe symptoms following transmission to greenhouse-grown trees, like the donor trees grown in the field (Tables 1 and 2).

The second group of trees naturally infected by accessions $1 / 22$ through 8/7 developed severe symptoms several times during the 11-year observation period, often in an irregular order. For this reason, the average DI did not differ considerably at the end of the field-growing phase (Tables 1 and 2). At that time, however, when the accessions were graft-transmitted to trees subsequently grown in the greenhouse, symptomatology of the trees ranged from nonsymptomatic to severe. In most cases, these differences between the strains persisted in the five years of greenhouse growing. Exceptions are accessions $1 / 22$ and $2 / 3$, which induced distinct symptoms in the donor trees at time of grafting but did not cause symptoms when the recipient trees were grown in the greenhouse. The third group

Fig. 2. Phylogenetic and phytopathogenic clustering of 171 cloned 454bp $h f l B$ gene fragments of 15 single-strain accessions and 12 multiplestrain accessions from 'Candidatus Phytoplasma mali'-infected apple trees and four strains maintained in experimental hosts. Clones representing severe or mild strains are classified using the motifs CTT184 and TTA184, respectively. Additional markers for high virulence are nucleotides G215, A252, C267, A367, and A377. An additional marker for low virulence is the motif T-C227. Phylogenetic analyses were conducted in MEGA4 using the neighbor-joining parameters and the bootstrap test. The percentage of bootstrap values for 500 replicates is shown on the branches. The tree is drawn to scale, with branch lengths calculated using the average pathway method (Tamura et al. 2007). Extension of the accession designation shows clone number. Plant host extensions indicate sequences of accession 1/93 strains maintained in periwinkle or tobacco. Extensions following clone number or host name indicate the number of additional cloned fragments of the same accession with identical sequences. 
of accessions, which was obtained from symptomatic donor trees with unknown disease history (AT/2 through WS), continued to cause severe symptoms following transmission to trees subsequently grown in the greenhouse (Tables 1 and 2).
Virulence and molecular characteristics of single-strain accessions.

The single-strain accessions comprise 15 isolates from apple and reference strains AP15 and AT. In addition, two strains

Table 1. Correlation of virulence with single-strand conformation polymorphism (SSCP) profiles and phylogenetic clustering of cloned $h f l B$ gene sequences of single-strain accessions of 'Candidatus Phytoplasma mali'

\begin{tabular}{|c|c|c|c|c|c|c|c|c|c|}
\hline Accession & Field $^{\mathbf{a}}$ & Greenhouse $^{a}$ & SSCP profiles $^{\mathrm{b}}$ & Distinct profiles $^{b}$ & High $^{c}$ & Low $^{\mathrm{c}}$ & No. of DNA sequences & High $^{d}$ & Low $^{\text {d }}$ \\
\hline \multicolumn{10}{|c|}{ Inoculation 1993 (group 1) } \\
\hline $12 / 93$ & 2.4 & 3.0 & 10 & 1 & 10 & 0 & 6 & 6 & 0 \\
\hline \multicolumn{10}{|c|}{ Natural infection (group 2) } \\
\hline $2 / 4$ & 1.7 & 0.2 & 15 & 1 & 0 & 15 & 4 & 0 & 4 \\
\hline $3 / 1$ & 1.6 & 3.0 & 8 & 1 & 8 & 0 & 2 & 2 & 0 \\
\hline $3 / 2$ & 1.2 & 0.5 & 16 & 2 & 0 & 16 & 5 & 0 & 5 \\
\hline $3 / 3$ & 1.5 & 0.5 & 20 & 2 & 0 & 20 & 3 & 0 & 3 \\
\hline $3 / 5$ & 1.6 & 3.0 & 9 & 3 & 9 & 0 & 3 & 3 & 0 \\
\hline $3 / 6$ & 1.8 & 3.0 & 8 & 2 & 8 & 0 & 2 & 2 & 0 \\
\hline $3 / 8$ & 1.4 & 2.5 & 30 & 3 & 30 & 0 & 12 & 12 & 0 \\
\hline $8 / 7$ & 1.5 & 1.3 & 14 & 2 & 14 & 0 & 4 & 4 & 0 \\
\hline \multicolumn{10}{|c|}{ Inoculation 2005 (group 3) } \\
\hline $\mathrm{AT} / 2$ & $\mathrm{NA}^{\mathrm{e}}$ & 2.3 & 8 & 1 & 8 & 0 & 2 & 2 & 0 \\
\hline GDH1 & NA & 2.3 & 5 & 1 & 5 & 0 & 1 & 1 & 0 \\
\hline GDH4 & NA & 2.3 & 7 & 2 & 7 & 0 & 3 & 3 & 0 \\
\hline GDH6 & NA & 2.3 & 5 & 1 & 4 & 0 & 1 & 1 & 0 \\
\hline Rol & NA & 2.3 & 8 & 2 & 8 & 0 & 5 & 4 & 0 \\
\hline WS & NA & 2.8 & 4 & 1 & 4 & 0 & 2 & 2 & 0 \\
\hline \multicolumn{10}{|c|}{ Strains in experimental hosts ${ }^{\mathrm{f}}$} \\
\hline 1/93-tobacco & 0.2 & 0.2 & 26 & 1 & 0 & 26 & 4 & 0 & 4 \\
\hline 1/93-periwinkle & 0.2 & 0.2 & 36 & 1 & 0 & 36 & 13 & 0 & 13 \\
\hline AP15 & 3.0 & 2.5 & 6 & 1 & 6 & 0 & 1 & 1 & 0 \\
\hline AT & 3.0 & 2.5 & 21 & 1 & 21 & 0 & 3 & 3 & 0 \\
\hline
\end{tabular}

${ }^{a}$ Collective symptom and virulence values of field growing or of greenhouse growing and at sampling are based on a rating scheme from 0 (no symptoms/virulence) to 3 (severe symptoms and virulence).

b Number of SSCP and distinct profiles.

${ }^{\mathrm{c}}$ Number of profiles indicating high or low virulence based on molecular classification of corresponding or comparable sequences.

${ }^{\mathrm{d}}$ Number of DNA sequences indicating high or low virulence based on phylogenetic clustering of nucleotide and derived amino acid sequences and molecular markers.

${ }^{\mathrm{e}}$ Not applicable.

${ }^{\mathrm{f}}$ Virulence estimation based on Carraro et al. 1988, Marwitz et al. 1974, and on virulence in periwinkle.

Table 2. Correlation of virulence with single-strand conformation polymorphism (SSCP) profiles and phylogenetic clustering of cloned $h f l B$ gene sequences of multiple-strain accessions of 'Candidatus Phytoplasma mali'

\begin{tabular}{|c|c|c|c|c|c|c|c|c|c|}
\hline Accession & Field $^{\mathrm{a}}$ & Greenhouse $^{\mathrm{a}, \mathrm{b}}$ & $\operatorname{SSCP}^{\mathrm{c}}$ & Distinct $^{\mathrm{c}}$ & High $^{\mathrm{d}}$ & Low $^{\mathrm{d}}$ & DNA sequences $^{\mathrm{d}}$ & High $^{\mathrm{e}}$ & Low $^{\mathrm{e}}$ \\
\hline \multicolumn{10}{|c|}{ Inoculation 1993 (group 1) } \\
\hline $1 / 93$ & 0.4 & $0.2 \mathrm{R}$ & 34 & 3 & 1 & 33 & 8 & 1 & 7 \\
\hline $1 / 93$ & 0.4 & $0.2 \mathrm{~S}$ & 95 & 2 & 2 & 93 & 20 & 1 & 19 \\
\hline $1 / 93$ & 0.4 & $2.2 \mathrm{~S}$ & 29 & 2 & 27 & 2 & 4 & 4 & 0 \\
\hline $3 / 93$ & 2.4 & $3.0 \mathrm{R}$ & 15 & 2 & 13 & 2 & 9 & 8 & 1 \\
\hline $4 / 93$ & 0.6 & $0.3 \mathrm{R}$ & 15 & 2 & 2 & 13 & 5 & 2 & 3 \\
\hline 4/93 & 0.6 & $2.2 \mathrm{~S}$ & 10 & 2 & 9 & 1 & 3 & 2 & 1 \\
\hline $8 / 93$ & 2.8 & $3.0 \mathrm{R}$ & 8 & 2 & 7 & 1 & 4 & 3 & 1 \\
\hline $10 / 93$ & 1.7 & $1.5 \mathrm{R}$ & 15 & 5 & 11 & 4 & 8 & 4 & 4 \\
\hline $13 / 93$ & 1.1 & $0.2 \mathrm{R}$ & 8 & 3 & 0 & 8 & 3 & 0 & 3 \\
\hline $14 / 93$ & 2.0 & $0.5 \mathrm{R}$ & 16 & 2 & 14 & 2 & 3 & 2 & 1 \\
\hline $14 / 93$ & 2.0 & $3.0 \mathrm{~S}$ & 8 & 1 & 7 & 1 & 2 & 2 & 0 \\
\hline $17 / 93$ & 0.1 & $0 \mathrm{R}$ & 14 & 3 & 2 & 12 & 6 & 1 & 5 \\
\hline \multicolumn{10}{|c|}{ Natural infection (group 2) } \\
\hline $1 / 22$ & 1.4 & $0 \mathrm{~S}$ & 7 & 4 & 3 & 4 & 5 & 2 & 3 \\
\hline $2 / 3$ & 2.2 & $0 \mathrm{~S}$ & 6 & 2 & 3 & 3 & 4 & 2 & 2 \\
\hline $2 / 7$ & 1.5 & $0.3 \mathrm{~S}$ & 13 & 2 & 1 & 12 & 8 & 1 & 7 \\
\hline \multicolumn{10}{|c|}{ Inoculation 2005 (group 3) } \\
\hline GDH1-CF & $N A^{f}$ & $2.6 \mathrm{~S}$ & 8 & 2 & 8 & 0 & 3 & 3 & 0 \\
\hline
\end{tabular}

${ }^{a}$ Collective virulence value of field-growing period. Symptom and virulence values are based on a rating scheme from 0 (no symptoms/virulence) to 3 (severe symptoms/virulence).

${ }^{\mathrm{b}}$ Virulence values of greenhouse growing or at sampling, or both. Root samples (R) were collected from field-grown trees, and shoots samples (S) were collected from trees graft-inoculated with scions from the field-grown trees and maintained in the greenhouse.

${ }^{\mathrm{c}}$ Number of SSCP and distinct profiles.

${ }^{\mathrm{d}}$ Number of profiles indicating high or low virulence and number of DNA sequences examined based on molecular classification of corresponding or comparable sequences.

${ }^{\mathrm{e}}$ Number of clones indicating high or low virulence based on phylogenetic clustering of nucleotide and derived amino acid sequences and molecular markers.

${ }^{\mathrm{f}}$ Not applicable. 
from multiple-strain accession 1/93 that were separated by their specific growth in tobacco and periwinkle (Seemüller et al. 2010) were included in this group because no other components of the 1/93 complex were identified in these experimen-



tal hosts. Except for the field-growing phase of accessions 2/4 through 8/7, all accessions showed consistent pathological data. At the time of sampling in the greenhouse-growing period, they were classified as either mild or severe. Cloned sequences of these strains were homogenous and clustered separately for virulent and mild accessions (Table 1; Fig. 2). Sequences of highly virulent accessions 3/5, 3/6, GDH1, GDH4, and GDH6 cluster closely together in the same branch. The same applies for reads of severe strains 3/8, 12/93, Rol, and WS, which cluster at the same branch, and of strains $8 / 7$ and AT/2, which cluster together at a different position. On the other hand, sequences of mild strains $3 / 2$ and $3 / 3$, of $2 / 4$ and 1/93-tobacco, and of 1/93-periwinkle cluster together at distinct positions in the same major subclade. The sequence data are supported by the results of SSCP analysis, in which considerably more clones were examined than by sequencing (Table 1). Due to the data obtained by direct comparison of SSCP patterns and sequences, it was possible to interpret the SSCP profiles of $h f l B$ fragments that were not sequenced. An example are strains 3/5, 3/6, GDH1, GDH4, and GDH6, which showed a unique profile indicative for high virulence and clustered closely together. In addition, the predominant profile of phylogenetically closely related strains $3 / 8,12 / 93$, Rol, and WS are very similar. Alike, mild strains $2 / 4,3 / 2$ and $3 / 3$ showed SSCP profiles and sequence clustering resembling each other (Figs. 1 and 2).

Clustering of severe and mild single-strain accessions was linked to molecular markers at the nucleotide and deduced amino acid level (Figs. 2 and 3). At the nucleotide level, there are the motifs CTT184 and TTA184 at position 184 to 186 of the $h f l B$ fragments, which distinguish severe and mild strains, covering all sequences. The CTT184-based classification of severe strains is supported by nucleotide markers G215, A252, C267, A367, and A377, whereas classification of several mild strains is supported by motif TTGCTGC227 (T-C227) at position 227 to 233 (Fig. 4). Of these markers, CTT184, TTA184, $\mathrm{A} 252$, and $\mathrm{C} 267$ are based on synonymous substitutions, whereas the markers at positions G215, T-C227, A367, and A377 lead to nonsynonymous substitutions (Fig. 4). As shown in the amino acid-based tree (Fig. 3), the amino acid markers cover only about half of the strains. However, the amino acid markers can be considered as stronger than those based on translationally irrelevant mutations because they are closely linked to particularly severe strains such as $3 / 1,3 / 5,3 / 6,14 / 93$, and the GDH group, as well as to very mild strains, including components of multiple-strains accessions 1/93 and 17/93 (Fig. 3).

\section{Virulence and molecular characteristics of multiple-strain accessions.}

Classification of multiple-strain accession components is based on the results obtained with severe and mild single-strain

Fig. 3. Phylogenetic and phytopathogenic clustering of the putative translation products of the $h f l B$ gene fragments of 15 single-strain accessions and 12 multiple-strain accessions from 'Candidatus Phytoplasma mali'infected apple trees and four strains maintained in experimental hosts. Amino acids S72, S123, and Y126 are indicative for high virulence and the motif FAA76 is indicative for low virulence. Phylogenetic analyses were conducted in MEGA4 using the neighbor-joining parameters and the bootstrap test. The percentage of bootstrap values for 500 replicates is shown on the branches. The tree is drawn to scale, with branch lengths calculated using the average pathway method (Tamura et al. 2007). Extension of the accession designation show clone number. Plant host extensions indicate sequences of accession 1/93 strains maintained in periwinkle or tobacco. Extensions following clone number or host name indicate the number of additional cloned fragments of the same accession with identical sequences. 
accessions in that components representing severe strains clustered with severe strains and components representing mild strains clustered with mild strains. Analysis of the molecular data indicates that, except for accession GDH1-CP, all multiple-strain accessions are composed of severe and mild strains. However, the ratio of the two categories depends on the symptom values of the infected trees at the time of sampling (Table 2). For example, 24 of 26 cloned $h f l B$ gene fragments derived from root and shoot samples of largely nonsymptomatic trees infected by mild accession 1/93 and grown in the field or in the greenhouse clustered at two positions with other mild strains (e.g., sequences $1 / 93-3+9$ and 1/93-100+7). Only two sequences (1/93-80, 1/93-81) clustered with severe strains. In contrast, the DNA sample from the only one of the five greenhouse-grown trees that developed severe symptoms yielded, exclusively, sequences clustering with severe strains (1/93-79, 1/93-101+2) (Fig. 2). Like most of the clones derived from not or weakly affected trees infected by key accession 1/93, the sequences of mild accessions $17 / 93$ and $2 / 7$ clustered predominantly with mild strains. The opposite was the case when severe accessions were examined. DNA samples from highly virulent accessions 3/93, 8/93, and 14/93 yielded mostly sequences clustering with severe strains. Only three sequences of these accessions (3/93-31, 8/93-108, 14/93-47) clustered with mild strains. The clustering positions of all sequences of severe accession GDH1-CP indicated strong virulence. In the moderately virulent accessions 4/93 and 10/93, both sequence categories occurred in about the same number (Table 2; Fig. 2).

While symptom expression and variation in symptomatology of the multiply infected trees described above may be explained by strain composition and by shifts in the phytoplasma population, another phenomenon was observed by analyzing accessions $1 / 22$ and $2 / 3$. Both showed high virulence indices in the field-growing period. However, in the greenhouse-growing phase of the inoculated trees, no symptoms were observed. Sequence analysis revealed the equal presence of mild and severe strains, thus possibly reflecting both the current disease situation and disease history (Table 2; Figs. 2 and 3).

In contrast to the finding that all severe strains of singlestrain accessions are characterized by their association with both the basic CTT184 motif and one to three additional singlenucleotide markers, this multiple linkage between virulence and molecular markers does not apply for all strains of multiplestrain accessions clustering in the lower CTT184 segment (Fig. 2). Of the 63 genotypes clustering in the two CTT184 segments, 52 showed this characteristic, whereas 11 showed the CTT184 motif alone. From pathological data, there is some indication that the CTT184 motif alone has not the same strength as multiple linkages. This is evidenced by comparing the highly virulent group consisting of accessions 3/8, 12/93, Rol, and WS (Fig. 2, bottom) with the adjacent sequences of accessions $2 / 7$ (sequences 128+2, 146, 147, 175), 10/93 (sequences 42, 46, $61+1$ ), and $13 / 93$ (sequences $124,125,141$ ) that predominantly show pathological data indicating low or moderate virulence. While the former group, in addition to motif CTT184, is associated with the nucleotide markers A252 and C267, the second group does not show additional linkages. For this reason, the indicated sequences of the latter accessions are classified as representing mild strains (Table 2).

Another deviation from the classification principle based on the motifs CTT184 and TTA184 is the grouping of sequences $1 / 22-177,2 / 3-179$, and 4/93-144. These reads cluster in the sector of the low-virulence marker TTA184 but are also linked with amino acid markers S123 and Y126, which we consider as strong markers for high virulence. This fact appears to justify overruling the TTA184 motif and classification of these sequences as representing highly virulent strains (Table 2; Figs. 2 and 3$)$.

\section{DISCUSSION}

Although AP is one of the most intensively studied phytoplasmal diseases, several aspects, such as the inconsistent symptom expression, are still poorly understood. Due to the observation that recovered trees are often only infected in the roots but the pathogen cannot be detected in the aerial parts (Carraro et al. 2004; Seemüller et al. 1984a), it is likely that the colonization behavior of ' $C a$. P. mali' is an important factor in recovery. As phytoplasmas depend, in their plant hosts, on functional sieve tubes and as the phloem in the aerial parts of apple trees degenerates during winter, the pathogen overwinters in the roots, in which intact sieve tubes are present all year long. From the roots, the stem may be recolonized in the spring, when new phloem is being formed. However, recolonization does not take place every year or the titer in the stem remains low. In both cases, severe aerial symptoms, which usually depend on high phytoplasma titers, will not be developed (Schaper and Seemüller 1982; Seemüller et al. 1984a and b). Ultrastructural, cytochemical, and gene expression analyses of phloem of healthy, visibly diseased, and recovered apple trees revealed various differences. Recovered trees are characterized by the presence of hydrogen peroxide $\left(\mathrm{H}_{2} \mathrm{O}_{2}\right)$, callose and phloem protein accumulation, and the upregulation of genes involved in synthesis of callose and phloem protein (Musetti et al. 2004, 2010).

In the current study the virulence of 27 ' $\mathrm{Ca}$. P. mali' accessions collected from three different groups of trees was observed over a time period of six to 17 years. This collection showed all major characteristics of AP disease, namely, expression of severe symptoms at the onset of disease, inconsistent symptomatology, recovery, reappearance of disease, and great differences in the virulence of the infecting phytoplasmas. From our work, there is evidence that a major reason for the unusual symptomatology of AP is the obviously widespread occurrence of multiple infections. Our study revealed that about half of the accessions examined were multiply infected

\section{A}


Mild

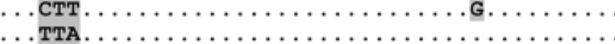

B



Fig. 4. Virulence-related markers in the A, nucleotide and B, deduced amino acid sequence of $h f l B$ gene fragments of 'Candidatus Phytoplasma mali' accessions. The markers occur singly or in combination. The nucleotide markers G215, A367, A377, and motif T-C227 correspond to the amino acid markers S72, S123, S126, and motif F-A76, respectively. 
and were composed of two to five distinct strains. Multiple infections may even be more widespread and may be difficult to identify when components occur in low numbers. In our attempt to molecularly characterize the virulence of ' $\mathrm{Ca}$. P. mali' strains, we investigated the relationship between symptomatology and molecular traits of the infecting phytoplasmas. This effort was greatly facilitated by the availability of singlestrain accessions. Cloning of $h f l B$ gene fragments of severe and mild strains of such accessions resulted in two types of sequences that clustered separately in phylogenetic analysis. This fact and the wide range of single-strain accessions led us to the experimental proof that nearly all multiple-strain accessions are composed of mild and severe strains and to classify the cloned sequences accordingly. The separate clustering of clones representing severe and mild strains was supported by a range of molecular markers at the nucleotide and amino acid level. Using the motifs CTT184 and TTA184 as markers, it was possible to basically distinguish and classify severe and mild strains, respectively. In most cases this differentiation is corroborated by one to three additional markers.

The molecular classification of the components of multiplestrain accessions reflects their virulence. Cloned sequences of highly virulent accessions clustered predominantly with sequences of severe strains, whereas sequences of mild accessions clustered mainly with sequences of mild strains. However, shifts in the phytoplasma composition may occur that drastically alter virulence. There is some indication that growing conditions may trigger such shifts, which seem to play an important role in the symptomatology of AP phytoplasma-infected trees. Our data also indicate that another mechanism may exist leading to low virulence. Accessions $1 / 22$ and $2 / 3$ proved to be virulent until the end of the field-growing period but did not develop any symptom following graft transmission and greenhouse growing. As sequences representing mild and severe strains were present in equal numbers, it is conceivable that virulence factors were inhibited by action of the mild strain components.

The high copy numbers of $h f l B$ genes in phytoplasmas is unusual in other prokaryotes, including the close phytoplasma relative Acholeplasma laidlawii (GeneBank accession number CP000896.1), which has only one $h f l B$ gene. It thus is unlikely that this abundance derives from ancestral mollicutes. Instead, examination of ' $\mathrm{Ca}$. P. asteris' strains AY-WB and OY-M indicate that part of the $h f l B$ genes derive from other sources. They cluster together with other multicopy genes in so-called potential mobile units (PMU). These PMU are typically flanked by transposase gene tra5, which plays a key role in transposition and rearrangements and is likely responsible for duplication and transfer events of PMU-based genes in the genome (Arashida et al. 2008; Bai et al. 2006). Indication of the effective mobility of PMU has been obtained by the finding that PMU1 of ' $\mathrm{Ca}$. P. asteris' AY-WB may occur as both a linear form in the chromosome and extrachromosomal as a circular form (Toruño et al. 2010).

The circular chromosomes of strains OY-M and AY-WB and ' $\mathrm{Ca}$. P. australiense' are rich in repeated genes, of which many occur in PMU and PMU-like elements. These and other putative insertions result in a discontinuous GC skew, indicating frequent recombination and genome instability (Arashida et al. 2008; Bai et al. 2006; Tran-Nguyen et al 2008). By contrast, ' $\mathrm{Ca}$. P. mali' is characterized by a linear chromosome consisting of the core region and terminal inverted repeats (TIR). Completely sequenced strain AT has few repeated genes, a regular GC skew, and only two truncated derivatives of putative PMU. Only one of them has a single flanking tra5 gene, and inverted repeats are completely missing. Only $h f l B$ ATP00406 lies in one of these putative PMU. In contrast ATP00464 is mainly located in one of the highly conserved TIR and extends into the more variable core (Kube et al. 2008). This gene is unlikely to be prone to recombination and mobilization events. Transcription of this gene has been established (Schneider and Seemüller 2009).

Due to their limited metabolic capabilities, phytoplasmas depend on their hosts. They are thus equipped with appropriate transport systems for the uptake of the required nutrients. They also require efficient secretion systems for introducing effector proteins such as toxins, adhesins, and hydrolytic enzymes to attack or manipulate, or both, their hosts (Hogenhout et al. 2008). Although the high copy number of $h f l B$ genes seems to indicate their importance for these plant pathogens, it is not clear whether they are essential for parasitism. The ATP00464type $h f l B$ gene employed in our study encodes putative proteins of 599 amino acids in length. Analysis using the Phobius predictor (Käll et al. 2004) showed that the resulting proteins are anchored to the cytoplasmic membrane via two transmembrane segments, with the short $\mathrm{N}$ - and long $\mathrm{C}$-terminal parts facing the cytoplasma. The main cytosolic region consists of an $\mathrm{AAA}^{+}$-ATPase and a $\mathrm{Zn}^{2+}$ metalloprotease (unpublished results). Such metalloproteases are known to catalyze the degradation of denatured, misassembled, or damaged proteins, which helps to maintain quality control in the membrane and cytoplasma (Ingmer and Brondsted 2009; Lithgow et al. 2004). This suggests that the ATP00464-type HflB protein is essential for cellular function but is probably not directly involved in pathogenicity. However, from Staphylococcus aureus and Salmonella enterica, there is indication that $\mathrm{HflBs} / \mathrm{FtsHs}$ play a role in pathogenicity. It could be shown that the virulence factor MgtC of Salmonella enterica may be degraded by action of FtsH (Alix and Blanc-Potard 2008). On the other hand, mutation of ftsH in Staphylococcus aureus may lead to pleiotropic defects by affecting several physiological and biochemical processes and attenuating pathogenicity (Lithgow et al. 2004). Similar effects cannot be excluded for phytoplasmas.

In this study, we succeeded in determining and classifying phytoplasma virulence at the molecular level. In this way, it was possible to resolve the phytopathogenic composition of multiple-strain accessions and to estimate their importance for symptom expression and course of disease. As shown for key accession 1/93, the potential of multiple-strain accessions is not restricted to symptom expression in apple alone; it also may affect the host range as identified in transmission trials to periwinkle and tobacco. The early observations of aster yellows phytoplasmas strain interactions (Freitag 1964; Kunkel 1955; Valenta 1959) may also indicate that the interferences identified in our work are not restricted to the AP agent but are probably a widespread phenomenon in phytoplasmology. They are not only important to better understand virulence and inconsistent symptomatology, they also are of considerable importance for detection (primer, probe, and antibody specificity), identification, and classification. In addition, action of mild or suppressive strains, or both, may be responsible for the ultrastructural and cytochemical aberrations identified in recovered trees by Musetti and associates $(2004,2010)$.

\section{MATERIALS AND METHODS}

\section{Phytoplasma sources.}

Root or shoot scions from 27 apple trees naturally infected by ' $C a$. P. mali' were used to graft-inoculate healthy M 11 rootstocks. Infection of the scionwood was verified by PCR, using AP phytoplasma-specific primers (Lorenz et al. 1995). The scion cultivar of all trees was cv. Golden Delicious. A standard insecticide program was employed to protect the experimental plants from vector transmission of the AP phytoplasma. 
The donor trees consist of three groups. In the first group, accessions 1/93 through 17/93 were collected in 1993 from trees between 10 and 60 years old at several locations of southwestern Germany, with the exception of accession 1/93, which was sampled in Burgundy (France). From each accession, two rootstocks were graft-inoculated and were grown at the experimental field of the Julius Kuehn Institute (Dossenheim, Germany) until now. The occurrence of AP symptoms was annually recorded using a rating scheme from 0 (no symptom) to 3 (severe symptoms such as witches' brooms, stunting, or reduced fruit size). The final evaluation of virulence of these accessions after 12 years of growth revealed great differences as expressed in cumulative DI ranging from 1.0 to 33.3 (Seemüller and Schneider 2007). In 2005, root scions of accessions 1/93, 4/93, 12/93, and 14/93 were used to inoculate healthy rootstocks. These trees were subsequently grown in an unheated greenhouse until now. Using dodder (Cuscuta europea) bridges, two strains of the multiple-strain accession 1/93 were transmitted to periwinkle (Catharanthus roseus) and tobacco (Nicotiana occidentalis and $N$. tabacum). They grew specifically in one of these hosts (Seemüller et al. 2010) and were maintained by periodic grafting in an insect-proof greenhouse. ' $\mathrm{Ca}$. P. mali' reference strains AT (Marwitz et al. 1974) and AP15 (Carraro et al. 1988) were also maintained in these hosts under these conditions.

The second group, consisting of accessions 1/22 through $8 / 7$, was collected from trees planted in 1993 at the Julius Kuehn Institute and were observed under natural infection conditions for 11 years for disease appearance. During the observation period, all trees showed temporarily severe symptoms. The third group is composed of accessions Rol, WS, and the GDH group, which were collected at or near the Julius Kuehn Institute, and of accession AT/2, which originate in the province of Trento (Italy). The disease history of these sources is unknown. However all donor trees showed severe symptoms at the time of sampling. In 2005, all accessions of the second and third groups were graft-inoculated to several rootstocks and were maintained in an unheated greenhouse until now. Appearance and severity of disease of all greenhouse-maintained trees was annually recorded as described. To receive comparable data for all groups, the cumulative indices from field- and greenhouse-grown trees were divided by the years of observation. The figures obtained were used for evaluating both symptomatology and virulence.

\section{DNA extraction and PCR amplification.}

Either root, the current season's shoot samples, or both were taken from infected apple trees. Shoot samples were collected in late summer or early fall. DNA was extracted from phloem preparations of roots or shoots using a cetyltrimethylammonium bromide $(\mathrm{CTAB})$ procedure (Seemüller and Schneider 2007). The CTAB method was also used to isolate DNA from leaf midribs of periwinkle and tobacco.

The internal 528-bp fragment of ATP00464 hflB gene homologs used for phytopathogenic classification was amplified employing internal primer pair fHflB3_1 and rHflB3 (5'TTCTAGCTATTCATCGTGAA-3' and 5'-CGGCGCGATT AGTAGCTCC-3') as previously described (Schneider and Seemüller 2009). To amplify the full-length ATP00464 gene and its paralogs ATP00034, ATP00454, and ATP00457, primers fAP464 and rAP464 (5'-TATGATTTTGTAGGCGAA


fAP34 and rAP34 (5'-TTTTTCTGCGTGTATGAATAAT-3' and 5'-TAGACAAAAATTAAAAATATAATAAGG-3'), FATP454 and rATP454 (5'-TTCCGCTTGAGTAATCGTTTC-3' $/ 5^{\prime}$-TTC CTTAATTGAAGCGGTGTC-3'), and fAP457 and rAP457 (5'GAATTCATATCGAATTCTTTTTTTTG-3' and 5'-TCTTTTCT
TTTGTGGGGATTG-3'), respectively, were designed from the ' $C a$. P. mali' AT complete sequence and a draft sequence of strain 1/93-tobacco (Kube et al. 2008; unpublished results). They bind in the intergenic regions flanking the respective gene. In addition, internal primers AP464int (5'-TCTAAATC TTTAATTACTTCCAAAC-3'), AP34int (5'-ATACGAAACCA TAGGGGCTG-3'), and AP457int (5'-GACCACCAGGTACC GGTAAA-3') were used to complete the sequences. Amplification was performed in $25-\mu \mathrm{l}$ reactions containing $0.5 \mu \mathrm{M}$ of each primer, $1 \times$ polymerase buffer, $0.6 \mathrm{U}$ Taq polymerase (both Invitrogen, San Diego, CA,. U.S.A.), and $0.1 \mathrm{mM}$ each dNTP. The reaction was cycled with the following parameters: 5 min initial denaturation at $95^{\circ} \mathrm{C}$, followed by 35 cycles at $95^{\circ} \mathrm{C}$ for $1 \mathrm{~min}, 52^{\circ} \mathrm{C}$ for $45 \mathrm{~s}$, and $70^{\circ} \mathrm{C}$ for 1.5 or $2.0 \mathrm{~min}$. The final step was $5 \mathrm{~min}$ at $70^{\circ} \mathrm{C}$.

\section{Cloning, sequencing, and phylogenetic analysis.}

ATP0046-type $h f l B$ gene fragments and full-length genes of the ATP00464 paralog group obtained by PCR amplification were ligated into pGEM-T Easy vector system (Promega, Madison, WI, U.S.A.) and were transformed to Escherichia coli XL1 Blue cells (Stratagene, La Jolla, CA, U.S.A.). Colony PCR was employed to amplify the inserts of recombinant plasmids, using primer pair fHflb3_1 and rHflB3 for the ATP00464-type $h f l B$ gene fragments and standard M13 primers for the full-length genes. PCR products of $h f l B$ fragments were subjected to SSCP analysis as previously described (Schneider and Seemüller 2009). Several representative clones of each profile category were selected and propagated in Luria Bertani medium. DNA of recombinant plasmids was extracted using a miniprep kit (Qiagen, Hilden, Germany). Cloned fragments were sequenced using M13 forward and reverse primers. Following propagation and miniprepping, full-length $h f l B$ genes were sequenced, using M13 forward and reverse primers and the internal primers listed above. Alignment of sequences was performed with ClustalX2 (Thompson et al. 1997). For phylogenetic comparison, a 454-bp fragment was selected and analyzed employing the MEGA4 program using neighborjoining parameters and bootstrap analysis (Tamura et al. 2007). Part of the data from 14 of the 27 accessions included in this study derived from previous work on phylogenetic diversity and identification of multiple infections by ' $\mathrm{Ca}$. P. mali' (Seemüller et al. 2010).

\section{ACKNOWLEDGMENTS}

This work was supported as part of the Apple Proliferation Project by the Fondazione Edmund Mach Research Center at S. Michele all' Adige (Italy). We thank F. Hergenhahn for excellent technical assistance and W. Jarausch for providing strain AT/2.

\section{LITERATURE CITED}

Alix, E., and Blanc-Potard, A. B. 2008. Peptide-assisted degradation of the Salmonella MgtC virulence factor. EMBO (Eur. Mol. Biol. Organ.) J. 27:546-557.

Arashida, R., Kakizawa, S., Hoshi, A., Ishii, Y., Jung, H. Y., Kagiwada, S., Yamaji, Y., Oshima, K., and Namba, S. 2008. Heterogeneic dynamics of the structures of multiple gene clusters in two pathogenetically different lines originating from the same phytoplasma. DNA Cell Biol. 27:209217.

Bai, X., Zhang, J. H., Ewing, A., Miller, S. A., Radek, A. J., Shevchenko, D. V., Tzukerman, K., Walunas, T., Lapidus, A., Campbell, J. W., and Hogenhout, S. A. 2006. Living with genome instability: The adaptation of phytoplasmas to diverse environments of their insect and plant hosts. J. Bacteriol. 188:3682-3696.

Carraro, L., Osler, R., Refatti, E., and Poggi Pollini, C. 1988. Transmission of the possible agent of apple proliferation to Vinca rosea by dodder. Riv. Patol. Veg., Ser. 4, 24:43-52.

Carraro, L., Ermacora, P., Loi, N., and Osler, R. 2004. The recovery phe- 
nomenon in apple proliferation-infected apple trees. J. Plant Pathol. 86:141-146.

Danet, J. L., Bonnet, P., Jarausch, W., Carraro, L., Skoric, D., Labonne, G., and Foissac, X. 2007. Imp and secY, two new markers for MLST (multilocus sequence typing) in the $16 \mathrm{SrX}$ phytoplasma taxonomic group. Bull. Insectol. 60:339-340.

Freitag, J. H. 1964. Interaction and mutual suppression among three strains of aster yellows virus. Virology 24:401-413.

Hogenhout, S. A., Oshima, K., Ammar, E. D., Kakizawa, S., Kingdom, H. and Namba, S. 2008. Phytoplasmas: Bacteria that manipulate plants and insects. Mol. Plant Pathol. 9:403-423.

Ingmer, H., and Brondsted, L. 2009. Proteases in bacterial pathogenesis. Res. Microbiol. 160:704-710.

Jarausch, W., Saillard, C., Dosba, F., and Bové, J. M. 1994. Differentiation of mycoplasmalike organisms (MLOs) in European fruit trees by PCR using specific primers derived from the sequence of a chromosomal fragment of the apple proliferation MLO. Appl. Environ. Microbiol. 60:2916-2923.

Jarausch, W., Saillard, C., Helliot, B., Garnier, M., and Dosba, F. 2000. Genetic variability of apple proliferation phytoplasmas as determined by PCR-RFLP and sequencing of a non-ribosomal fragment. Mol. Cell. Probes 14:17-24.

Käll, L., Krogh, A., and Sonnhammer, E. L. L. 2004. A combined transmembrane topology and signal peptide prediction method. J. Mol. Biol. 338:1027-1036.

Kison, H., Schneider, B., and Seemüller, E. 1994. Restriction fragment length polymorphism within the apple proliferation mycoplasmalike organism. J. Phytopathol. 141:395-401.

Kube, M., Schneider, B., Kuhl, H., Dandekar, T., Heitmann, K., Migdoll, A. M, Reinhardt, R., and Seemüller, E. 2008. The linear chromosome of the plant-pathogenic mycoplasma 'Candidatus Phytoplasma mali'. BMC Genomics 9:306.

Kunkel, L. O. 1955. Cross protection between strains of aster yellows. Adv. Virus Res. 3:251-273.

Lithgow, J. K., Ingham, E., and Foster, S. J. 2004. Role of the hprT-ftsH locus in Staphylococcus aureus. Microbiology 150:373-381.

Lorenz, K.-H., Schneider, B., Ahrens, U., and Seemüller, E. 1995. Detection of the apple proliferation and pear decline phytoplasmas by PCR amplification of ribosomal and nonribosomal DNA. Phytopathology 85:771-776.

Martini, M., Ermacora, P., Falginella, L., Loi, N., and Carraro, L. 2008. Molecular differentiation of 'Candidatus Phytoplasma mali' and its spreading in Friuli Venezia Giulia region (North-East Italy). Acta Hortic. 781:395-402.

Marwitz, R., Petzold, H., and Özel, M. 1974. Untersuchungen zur Übertragbarkeit des möglichen Erregers der Triebsucht des Apfels auf einen krautigen Wirt. Phytopathol. Z. 81:85-91.

Musetti, R., Di Toppi, L. S., Ermacora, P., and Favali, M. A. 2004. Recovery in apple trees infected with the apple proliferation phytoplasma: An ultrastructural and biochemical study. Phytopathology 94:203-208.
Musetti, R., Paolacci, A., Ciaffi, M., Tanzarella, O. A., Polizzotto, R. Tubaro, F., Mizzau, M., Ermacora, P., Badiani, M., and Osler, R. 2010. Phloem cytochemical modification and gene expression following the recovery of apple plants from apple proliferation disease. Phytopathology 100:390-399.

Oshima, K., Kakizawa, S., Nishigawa, H., Jung, H. Y., Wei, W., Suzuki, S., Arashida, R., Nakata, D., Miyata, S., Ugaki, M., and Namba, S. 2004. Reductive evolution suggested from the complete genome sequence of a plant-pathogenic phytoplasma. Nat. Genet. 36:27-29.

Schaper, U., and Seemüller, E. 1982. Condition of the phloem and the persistence of mycoplasmalike organisms associated with apple proliferation and pear decline. Phytopathology 72:736-742.

Schneider, B., and Seemüller, E. 2009. Strain differentiation of Candidatus Phytoplasma mali by SSCP and sequence analyses of the $h f l \mathrm{~B}$ gene. J. Plant Pathol. 91:103-112.

Seemüller, E., and Schneider, B. 2004. 'Candidatus Phytoplasma mali', 'Candidatus Phytoplasma pyri' and 'Candidatus Phytoplasma prunorum', the causal agents of apple proliferation, pear decline and European stone fruit yellows, respectively. Int. J. Syst. Evol. Microbiol. 54:1217-1226.

Seemüller, E., and Schneider, B. 2007. Differences in virulence and genomic features of strains of 'Candidatus Phytoplasma mali', the apple proliferation agent. Phytopathology 97:964-970.

Seemüller, E., Kunze, L., and Schaper, U. 1984a. Colonization behavior of MLO, and symptom expression of proliferation-diseased apple trees and decline-diseased pear trees over a period of several years. Z. PflKrankh. PflSchutz 91:525-532.

Seemüller, E., Schaper, U., and Zimbelmann, F. 1984b. Seasonal variation in the colonization patterns of mycoplasmalike organisms associated with apple proliferation and pear decline. Z. PflKrankh. PflSchutz 91:371-382.

Seemüller, E., Kiss, E., Sule, S., and Schneider, B. 2010. Multiple infection of apple trees by distinct strains of 'Candidatus Phytoplasma mali' and its pathological relevance. Phytopathology 100:863-870.

Tamura, K., Dudley, J., Nei, M., and Kumar, S. 2007. MEGA4: Molecular evolutionary genetics analysis (MEGA) software version 4.0. Mol. Biol. Evol. 24:1596-1599.

Thompson, J. D., Gibson, T. J., Plewniak, F., Jeanmougin, F., and Higgins, D. G. 1997. The ClustalX windows interface: Flexible strategies for multiple sequence alignment aided by quality analysis tools. Nucleic Acids Res. 24:4876-4882.

Toruño, T. Y., Music, M. S., Simi, S., Nicolaisen, M., and Hogenhout, S. A. 2010. Phytoplasma PMU1 exists as linear chromosomal and circular extrachromosomal elements and has enhanced expression in insect vectors compared with plant hosts. Mol. Microbiol. 77:1406-1415.

Tran-Nguyen, L. T. T., Kube, M., Schneider, B., Reinhardt, R., and Gibb, K. S. 2008. Comparative genome analysis of 'Candidatus Phytoplasma australiense' (subgroup tuf-Australia I; rp-A) and 'Ca. Phytoplasma asteris' strains OY-M and AY-WB. J. Bacteriol. 190:3979-3991.

Valenta,V. 1959. Interference studies with yellows-type plant viruses: Cross protection tests with European viruses. Acta Virol. (Prague) 3:65-72 